Article

\title{
Synthesis of Benzoxazine-Based N-Doped Mesoporous Carbons as High-Performance Electrode Materials
}

\author{
Haihan Zhang, Li Xu * and Guoji Liu * \\ School of Chemical Engineering and Energy, Zhengzhou University, Zhengzhou 450001, China; \\ 15736873061@163.com \\ * Correspondence: xuli@zzu.edu.cn (L.X.); guojiliu@zzu.edu.cn (G.L.)
}

Received: 14 November 2019; Accepted: 30 December 2019; Published: 6 January 2020

check for updates

\begin{abstract}
In this work, nitrogen-doped carbon materials (NCMs) were prepared using aniline-phenol benzoxazine (BOZ) or aniline-cardanol benzoxazine as the carbon precursor and SBA-15 as the hard template. The effects of the carbonization temperature $\left(700,800\right.$, and $\left.900^{\circ} \mathrm{C}\right)$ and different nitrogen contents on the electrochemical properties of carbon materials were investigated. The samples synthesized using aniline-phenol benzoxazine as precursors and treated at $900{ }^{\circ} \mathrm{C}$ (NCM-900) exhibited an excellent electrochemical performance. The specific capacitance was $460 \mathrm{~F} / \mathrm{g}$ at a current density of $0.25 \mathrm{~A} / \mathrm{g}$ and the cycle stability was excellent $(96.1 \%$ retention rate of the initial capacitance after 2000 cycles) in a $0.5 \mathrm{M} \mathrm{H}_{2} \mathrm{SO}_{4}$ electrolyte with a three-electrode system. Furthermore, NCM-900 also exhibited a high specific capacitance, comparable energy/power densities, and excellent cycling stability using a symmetrical electrode system. The characterization of the morphology and structure of the materials suggests it possessed an ordered mesoporous structure and a large specific surface area. NCM-900 could thus be considered a promising electrode material for supercapacitors.
\end{abstract}

Keywords: benzoxazine; nitrogen-doped mesoporous carbon; electrode material; electrochemical performance; supercapacitor

\section{Introduction}

As a type of energy-storage device, supercapacitors offer a promising solution for the fast storage the excess electrical energy [1,2]. Electrochemical double-layer capacitors (EDLCs) or supercapacitors have recently attracted the attention of many researchers due to their considerable capacity, high power density, wide operating temperature range, short charging time, and long cycle life [3-6]. Energy is stored in supercapacitors via the electrostatic accumulation of charge at the electrode surface. As the most commonly used electrode materials for supercapacitors, carbon materials show excellent electrical and thermal conductivity, a large specific surface area, and high chemical stability $[7,8]$.

The limited specific capacity of carbon materials restricts its application as a good electrode material. This is shown to be ameliorated by doping heteroatoms, such as nitrogen (N), boron (B), phosphorus $(\mathrm{P})$, and sulfur $(\mathrm{S})$, into the carbon structures $[9,10]$. Doped heteroatoms in carbon materials can effectively enhance the specific capacitance by adding pseudocapacitance, which arises from the redox reaction of the heteroatoms [11,12]. Furthermore, doping could improve the wettability between the electrolyte and the electrode material [13]. Among the doped carbons, nitrogen-doped carbon materials (NCMs) have been shown to be promising at improving the capacitance via surface faradaic reactions without sacrificing the high rate capability and long cycle life. The new NCMs show good electronic conductivity and they can be easily prepared at low cost. To our knowledge, nitrogen has become the most-studied doped heteroatom for carbonaceous electrode materials [14,15]. 
Two main methods for the preparation of heteroatom-doped carbon materials have been developed so far: in situ doping using nitrogen-containing precursors (such as urea-polymer [16], polyaniline (PANI) [17], cyanamide [18], dicyandiamide [19], melamine [20]) and the post-treatment of porous carbons (using $\mathrm{NH}_{3}$ or amines). In in situ doping, heteroatoms usually enter directly into the skeleton of the carbon materials. This method could resolve the problem of nitrogen-containing functional groups on the surface of the porous carbons, which decrease the available surface area and pore volume [21,22]. In our investigation, the heteroatom was introduced using benzoxazine as a carbon precursor. The benzoxazine-based porous carbon material introduces various organic elements, such as oxygen and nitrogen [23-25]. Meanwhile, the high surface area and ordered porous structure of electrode materials are also important factors that affect the performance of supercapacitors. The nanostructured porous materials synthesized using template mesoporous silica (e.g., SBA-15, MCM-41) usually meet the above material requirements. In this method, the carbon material can be obtained inside the pores of the silica template, which can easily be removed by the treatment of hydrofluoric acid or sodium hydroxide [26,27]. The recovered carbon material, which keeps the morphology of the silica host, has a controlled pore size and ordered porous structure. Thus, the application of templating agents (e.g., SBA-15, MCM-41) provides a good idea for the design of electrode materials with a controllable morphology [28]. To date, benzoxazine-based, heteroatom-doped carbon materials that are synthesized using the hard template have not been well studied.

In this paper, for the first time, we synthesized nitrogen-doped mesoporous carbons with two different precursors (aniline-phenol benzoxazine and aniline-cardanol benzoxazine). Through the hard template (SBA-15) synthetic method, we investigated the effect of these different phenol sources on the nitrogen content and the effect of the carbonization temperature on the structure of the carbon materials. The electrochemical properties were also investigated. Due to having almost the same microscopic morphology and the same type of heteroatom, the two carbon materials provided analogous superior electrochemical performance. However, the carbon materials with the higher nitrogen content (NCM, those produced using an aniline-phenol benzoxazine precursor) displayed better electrochemical properties than those with the lower nitrogen content (ACNCM, aniline-cardanol benzoxazine precursor).

\section{Experimental Section}

\subsection{Materials}

Aniline, phenol, cardanol, formaldehyde solution (37 $\mathrm{wt} \%$ ), toluene, tetrahydrofuran, anhydrous ether, and hydrofluoric acid were all of analytical grade and were purchased from Tianjin Comomi (Comomi, Hebei District, Tianjin, China); acetylene black and SBA-15 were purchased from Pioneer Nano (Pioneer Nano, Gulou District, Nanjing, China); and Nafion perfluorinated resin solution was purchased from Aldrich (Aldrich, Pudong District, Shanghai, China).

\subsection{Synthesis of Aniline-Phenol Benzoxazine}

Benzoxazine was synthesized according to the literature [29]. First, $0.2 \mathrm{M}$ aniline and $0.4 \mathrm{M}$ formaldehyde were dissolved in toluene $(50 \mathrm{~mL})$, and the mixture was stirred at $40{ }^{\circ} \mathrm{C}$ for $1 \mathrm{~h}$. Then, $0.2 \mathrm{M}$ phenol was added into the above mixture and refluxed at $110^{\circ} \mathrm{C}$. After $6 \mathrm{~h}$, the upper organic phase was transferred to a flask with one neck, and then distilled using rotary evaporators. The crude product was dissolved into anhydrous ether and washed three times with sodium hydroxide solutions (mass fraction: $5 \%$ ), and then washed with distilled water to $\mathrm{pH}$ 7.0. The product was dried at $60{ }^{\circ} \mathrm{C}$ in a vacuum oven for $24 \mathrm{~h}$ and the light yellow benzoxazine was obtained.

\subsection{Synthesis of Aniline-Cardanol Benzoxazine}

The synthesis method of aniline-cardanol benzoxazine was similar to the above method. First, $0.2 \mathrm{M}$ of aniline and $0.4 \mathrm{M}$ of formaldehyde solution were dissolved in toluene, and the mixture was stirred 
at $40{ }^{\circ} \mathrm{C}$ for $1 \mathrm{~h}$. Then, $0.2 \mathrm{M}$ of cardanol was added and refluxed at $110{ }^{\circ} \mathrm{C}$ for $6 \mathrm{~h}$. The toluene solvent was removed using a rotary evaporator. The mixture was dissolved in anhydrous ether and washed three times with sodium hydroxide solutions, and then washed with distilled water to $\mathrm{pH} 7.0$. The product was dried at $60{ }^{\circ} \mathrm{C}$ for $24 \mathrm{~h}$. The resulting light orange sticky substance was obtained.

\subsection{Synthesis of Carbon Materials}

First, benzoxazine (BOZ) was dissolved in tetrahydrofuran, forming a clear and homogeneous solution. Then, SBA-15 (mass ratio, BOZ:SBA-15 = 1:1) was added into the above solution and the mixtures were sonicated for $6 \mathrm{~h}$. In order to remove the tetrahydrofuran, the BOZ/SBA-15 composites were dried using a vacuum drying apparatus. After that, the BOZ/SBA- 15 composites were heated stepwise at 120,140 , and $160{ }^{\circ} \mathrm{C}$ for $1 \mathrm{~h}$ each; at 200 and $220^{\circ} \mathrm{C}$ for $2 \mathrm{~h}$ each; and finally at $230{ }^{\circ} \mathrm{C}$ for $1 \mathrm{~h}$. Next, different carbonization temperatures were adopted. The aniline-phenol BOZ/silica composites were carbonized at $400{ }^{\circ} \mathrm{C}$ for $2 \mathrm{~h}$ and at $700^{\circ} \mathrm{C}$ for $2 \mathrm{~h}$, at $400{ }^{\circ} \mathrm{C}$ for $2 \mathrm{~h}$ and at $800^{\circ} \mathrm{C}$ for $2 \mathrm{~h}$, or at $400{ }^{\circ} \mathrm{C}$ for $2 \mathrm{~h}$ and at $900^{\circ} \mathrm{C}$ for $2 \mathrm{~h}$, with a heating rate of $2{ }^{\circ} \mathrm{C} / \mathrm{min}$ under a high-purity nitrogen atmosphere. Furthermore, the aniline-cardanol BOZ/silica composite was carbonized at $400{ }^{\circ} \mathrm{C}$ for $2 \mathrm{~h}$ and at $900{ }^{\circ} \mathrm{C}$ for $2 \mathrm{~h}$ with a heating rate of $2{ }^{\circ} \mathrm{C} / \mathrm{min}$ under a high-purity nitrogen atmosphere. After carbonization, $20 \mathrm{wt} \%$ of $\mathrm{HF}$ aqueous solution was used to remove the silica template. After etching, the above mixtures were centrifuged and washed with distilled water to $\mathrm{pH}$ 7.0. The samples were dried by vacuum drying apparatus. The as-obtained samples were denoted as NCM-700, NCM-800, NCM-900, and ACNCM-900.

\subsection{Sample Characterization}

Fourier transform infrared spectroscopy (FTIR 300, American Nicolet Co., Ltd, Waltham, MA, USA) spectra were conducted in the $400-4000 \mathrm{~cm}^{-1}$ region. The samples were mixed with $\mathrm{KBr}$ powder and pressed in a pellet. In order to know the specific surface area (calculated according to the BET method), pore volume and pore size distributions (calculated by the BJH method), the nitrogen adsorption-desorption isotherms were conducted using an America Quantachrome Autosorb-iQ analyzer. The scanning electron microscopy (SEM, JSM-7500F, Osaka, Japan), transmission electron microscopy (TEM; FEI TalosF200S, Portland, OR, USA) and the X-ray diffraction (XRD, Cu $\mathrm{K} \alpha$ radiation, PANalytical B.V., Eindhoven, Netherlands) were used to characterize the morphology of carbon materials. The surface chemical species of the samples were examined using an X-ray photoelectron spectroscope (XPS; AXIS Supra, Tianjin, China).

\subsection{Electrochemical Measurements}

A three-electrode system was adopted to study the electrochemical behavior of carbon materials. In the three-electrode system, a saturated calomel electrode was the reference electrode and a platinum electrode was the counter electrode, the prepared carbon materials was the working electrode, and $0.5 \mathrm{M}$ $\mathrm{H}_{2} \mathrm{SO}_{4}$ was the electrolyte. The preparation of the working electrode involved a carbon: acetylene black: Nafion perfluorinated resin solution at an 8:1:1 mass ratio, where the three materials were mixed in ethanol. The mass of materials coated on each working electrode was $0.2 \mathrm{mg}$. Galvanostatic charge-discharge (GCD) and cyclic voltammetry (CV) were conducted using an electrochemical workstation (CHI660E, Shanghai, China) at room temperature. The potential scan rates of cyclic voltammetry $(\mathrm{CV})$ tests were $5,10,20,50$, and $100 \mathrm{mV} \mathrm{s}^{-1}$, and the voltage window was -0.2 to $0.8 \mathrm{~V}$. Electrochemical impedance spectroscopy (EIS) measurements were recorded from $10 \mathrm{mHz}$ to $100 \mathrm{kHz}$. The galvanostatic charge-discharge (GCD) experiments were conducted under current densities of 0.25 , $0.5,1,2.5$, and $5 \mathrm{~A} / \mathrm{g}$. The specific capacitance $(C, \mathrm{~F} / \mathrm{g})$ of the active material (galvanostatic discharge process) could be calculated using the following equation:

$$
C=\frac{I \times \Delta t}{m \times \Delta V}
$$


where $I(\mathrm{~A})$ is the constant discharge current, $\Delta t(\mathrm{~s})$ is the discharge time, $\Delta V(\mathrm{~V})$ is the voltage difference during discharge, and $m(\mathrm{~g})$ is the mass of carbon loaded into the working electrode.

In order to investigate the application of supercapacitors, a two-electrode system was also adopted. The carbon: acetylene black: poly(tetrafluoroethylene) (PTFE) binder at a 8:1:1 mass ratio was mixed. The slurry of the mixture was painted on the nickel foam (area of $1 \mathrm{~cm}^{2}$ ) and formed a symmetrical supercapacitor device. The mass loading of the active materials on each electrode was $2.5 \mathrm{mg} / \mathrm{cm}^{2}$. Galvanostatic charge-discharge (GCD) and cyclic voltammetry (CV) were conducted using an electrochemical workstation (CHI660E, Shanghai, China) at room temperature. The voltage window was -0.2 to $0.8 \mathrm{~V}$. The electrolyte was $6 \mathrm{M} \mathrm{KOH}$. The specific capacitance $(C, \mathrm{~F} / \mathrm{g})$, energy density $(E, \mathrm{Wh} / \mathrm{kg})$ and power density $(P, \mathrm{~W} / \mathrm{kg})$ were calculated from the discharge curves as follows [30]:

$$
\begin{aligned}
& C=\frac{2 \times I \times \Delta t}{m \times \Delta V}, \\
& E=\frac{C \times \Delta V^{2}}{2 \times 4 \times 3.6}, \\
& P=\frac{3600 \times E}{\Delta t},
\end{aligned}
$$

where $I(\mathrm{~A})$ is the constant charge-discharge current, $m(\mathrm{~g})$ is the mass of active material per electrode, $\Delta t(\mathrm{~s})$ is the discharging time, and $\Delta V(\mathrm{~V})$ is the potential range for the discharging process excluding the voltage drops (IR) value.

\section{Results and Discussion}

\subsection{Microstructure Characterization}

Two different benzoxazine precursors and carbon materials doped with heteroatoms were successfully synthesized. The preparation processes of the materials is illustrated in Figure 1.

The chemical structure of the BOZ monomer was confirmed using FTIR. The infrared spectrum of aniline-phenol benzoxazine is presented in Figure 2a. The bands at $1598 \mathrm{~cm}^{-1}$ and $1489 \mathrm{~cm}^{-1}$ corresponded to the benzene skeleton vibration. The bands at $1369 \mathrm{~cm}^{-1}$ were assigned to the stretching mode vibration of the $\mathrm{C}-\mathrm{N}-\mathrm{C}$ group from the oxazine ring. The bands at $1226 \mathrm{~cm}^{-1}$ and $1155 \mathrm{~cm}^{-1}$ were assigned to the symmetric and the asymmetric stretching mode vibrations of the $\mathrm{C}-\mathrm{O}-\mathrm{C}$ group in the oxazine ring, respectively. The bands at $942 \mathrm{~cm}^{-1}$ and $750 \mathrm{~cm}^{-1}$ were vibrations from the oxazine ring and viscous vibration of the benzene ring, respectively.

Figure $2 \mathrm{~b}$ gives the FTIR spectrum of aniline-cardanol benzoxazine, where the bonds at $1600 \mathrm{~cm}^{-1}$ and $1495 \mathrm{~cm}^{-1}$ represented the benzene ring skeleton. The bands at $1370 \mathrm{~cm}^{-1}$ corresponded to the stretching vibration of the $\mathrm{C}-\mathrm{N}-\mathrm{C}$ in the oxazine ring. The bands at $1241 \mathrm{~cm}^{-1}$ and $1198 \mathrm{~cm}^{-1}$ were assigned to the symmetric and asymmetric stretching vibration of $\mathrm{C}-\mathrm{O}-\mathrm{C}$ in the oxazine ring, respectively. The peak at $955 \mathrm{~cm}^{-1}$ was the characteristic absorption peak of the oxazine ring. The peak at $752 \mathrm{~cm}^{-1}$ was the absorption peak of the outward viscous vibration of the benzene ring. The above characteristic peaks strongly suggested the formation of benzoxazine.

The morphology of the carbon materials was characterized using scanning electron microscopy (SEM, Figure 3a-d) and transmission electron microscopy (TEM, Figure 3e,f). Figure 3a-d are SEM images of the carbon materials (NCM-700, NCM-800, NCM-900, and ACNCM-900). The SEM images showed that the obtained $\mathrm{N}$-doped carbon material had a rod-like structure. There were many channels in the rod structure. NCM-900 had a good dispersibility and uniformity due to the complete carbonization and a high nitrogen content. For the TEM images of NCM-900 and ACNCM-900 (Figure 3e,f), NCM-900 (Figure 3e) showed a more regular fringe arrangement than ACNCM-900 (Figure 3f). Within a certain range, as the nitrogen content increased, the porosity of the nitrogen-doped porous material also increased [31]. 


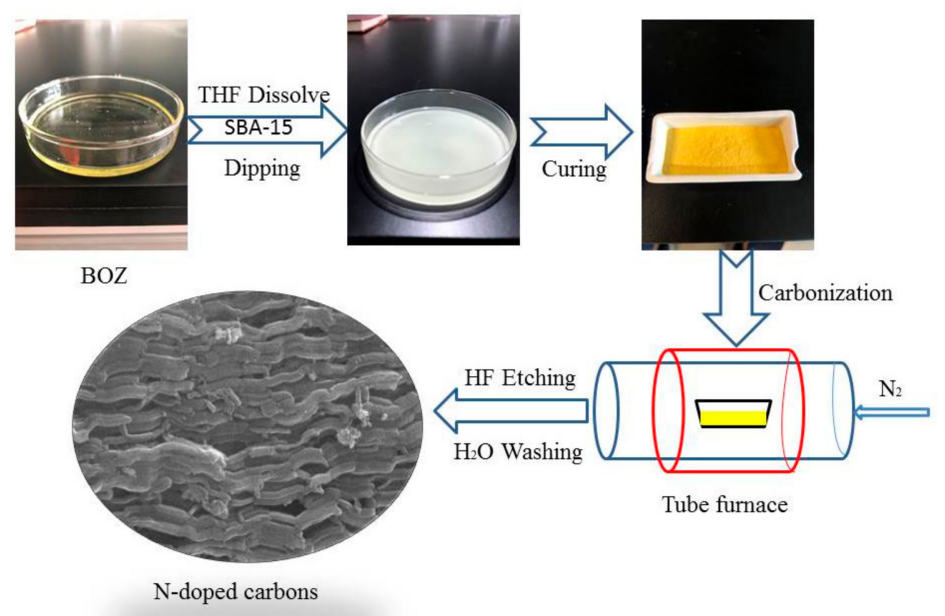

Figure 1. The preparation process for N-doped carbons using benzoxazine as precursor. BOZ: benzoxazine, HF: hydrofluoric acid.
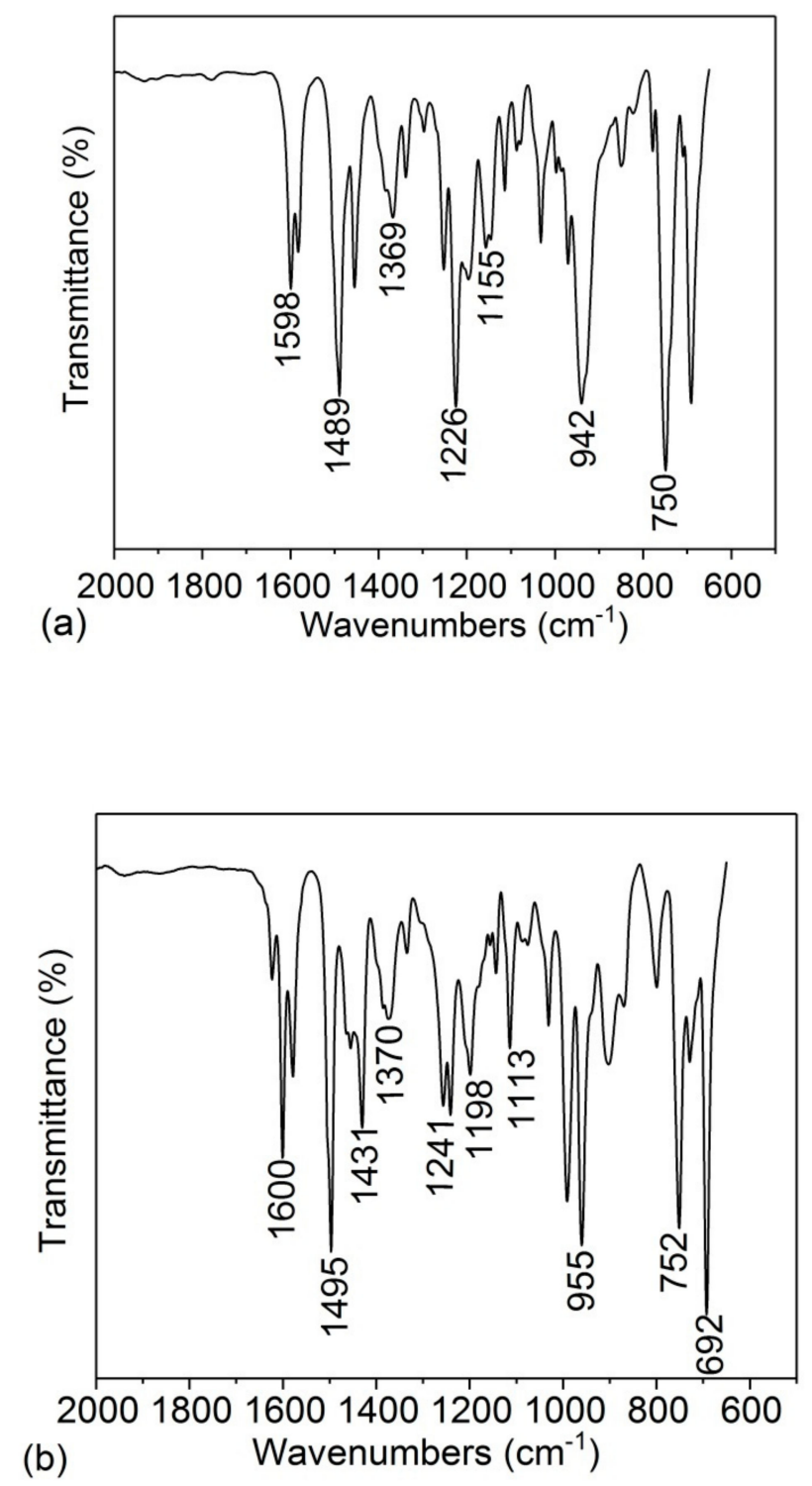

Figure 2. The FTIR of (a) aniline-phenol type benzoxazine and (b) aniline-cardanol type benzoxazine. 

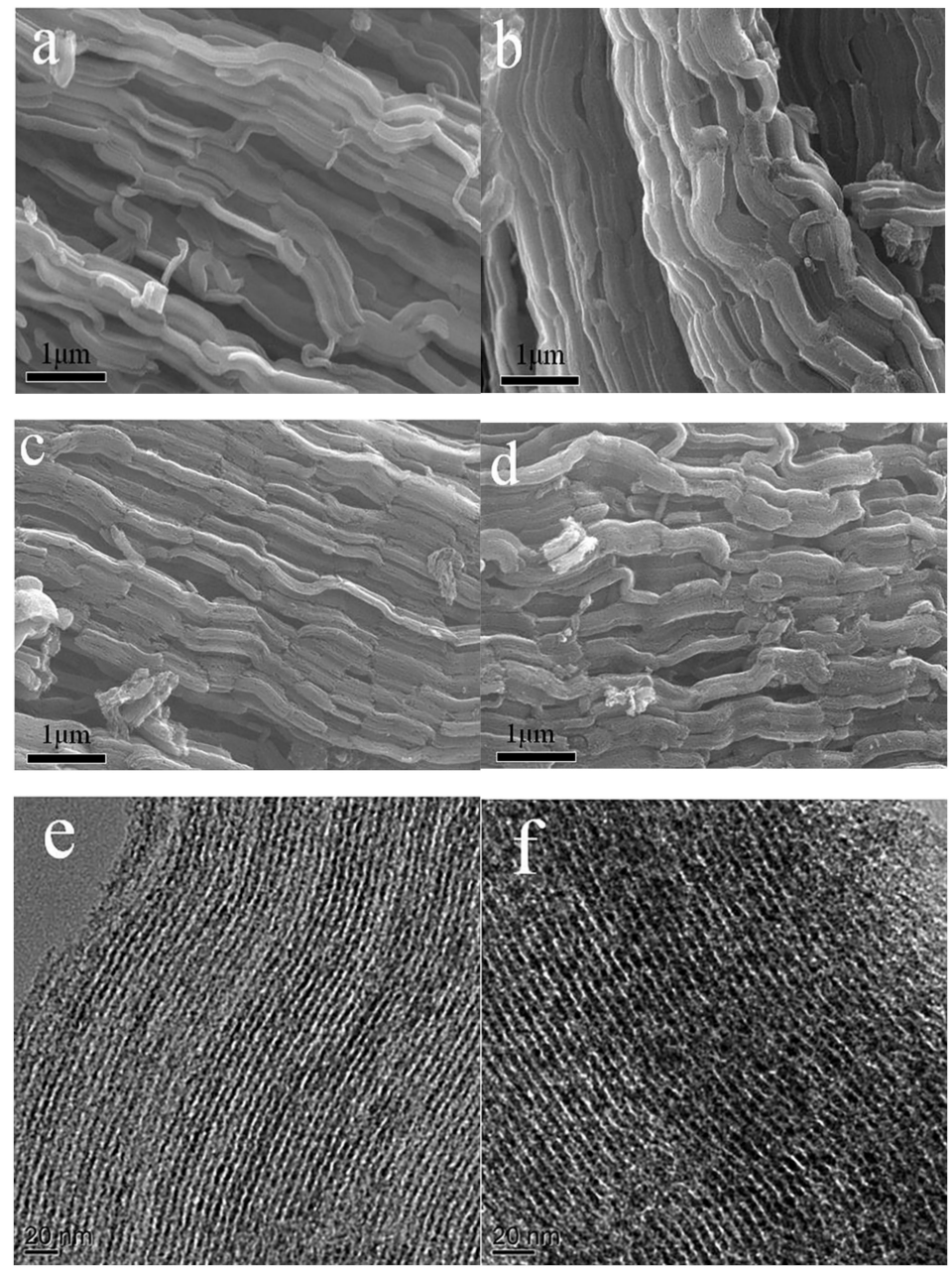

Figure 3. SEM images of (a) NCM-700, (b) NCM-800, (c) NCM-900, and (d) ACNCM-900; TEM images of (e) NCM-900 and (f) ACNCM-900.

The elemental compositions and nitrogen chemical states in NCM-900 and ACNCM-900 were characterized using X-ray photoelectron spectroscopy (XPS), as shown in Figure 4. The N 1s spectra of NCM-900 could be split into three peaks, corresponding to pyridinic $\mathrm{N}(397.5 \mathrm{eV})$, pyrrolic $\mathrm{N}(399.3 \mathrm{eV})$, and quaternary N (400.7 eV) (Figure 4a). The N 1s peaks of ACNCM-900 are shown in Figure 4b. It exhibited the same three nitrogen functional groups, centering at $398.1 \mathrm{eV}, 399.3 \mathrm{eV}$, and $400.6 \mathrm{eV}$, which were also assigned to pyridinic $\mathrm{N}$, pyrrolic $\mathrm{N}$, and quaternary $\mathrm{N}$, respectively [32]. In previous research, pyridinic $\mathrm{N}$ and pyrrolic $\mathrm{N}$ have been shown to have a positive effect at improving capacitive performance via pseudo-capacitance contribution due to configuration effects of separate electron pairs. Furthermore, the introduction of quaternary $\mathrm{N}$ could also facilitate electron transfer and enhance the conductivity of carbon materials [33-37]. The XPS peak analysis results of the two carbon materials are summarized in Table 1.

Small angle X-ray diffraction and wide-angle XRD were used to determine the structure of the produced carbon materials (NCM-700, NCM-800, NCM-900, and ACNCM-900) and SBA-15. The XRD patterns are presented in Figure $5 \mathrm{a}, \mathrm{b}$. The results of the XRD show that these carbon materials (NCM-700, NCM-800, NCN-900, and ACNCM-900) had an ordered and graphitized amorphous structure. The XRD also showed that these carbon materials (NCM-700, NCM-800, NCM-900, and ACNCM-900) had a similar structure to SBA-15. There were three well-resolved diffraction peaks $(100,110$, and 200) in the small angle X-ray diffraction (Figure 5a), which showed that the NCM materials had a 2D hexagonal symmetry with the space group p6mm. The wide-angle XRD of NCM-900 is shown in Figure $5 b$, which exhibited two diffraction peaks at $2 \theta=25^{\circ}$ and $44^{\circ}$ belonging to the (002) and (100) planes of hexagonal 
carbon, respectively [38,39]. We could find the graphitized and amorphous carbon structures of the NCM-900 from the wide angle XRD. These structures could enhance the electrochemical properties.

The nitrogen adsorption-desorption isotherms (Figure 5c) and pore size distribution (Figure 5d) indicated that these obtained carbon materials (NCM-700, NCM-800, NCM-900, and ACNCM-900) prepared using different carbonization temperatures and different precursors had typical type IV curves (according to the International Union of Pure and Applied Chemistry IUPAC classification) with a hysteresis loop (relative pressure, $P / P_{0}=0.4-0.7$ ) and a mesoporous structure [40].

The nitrogen adsorption-desorption isotherms of the four carbon materials were nearly similar in shape. Furthermore, compared with the curve of SBA-15 (Figure 5c), we found that the structure of the prepared carbon material came from the engraving of the template. From Figure $5 d$, for carbon materials prepared from the same precursor, the pore size distribution had no significant tendency even though the carbonization temperature was different. The average pore size was concentrated in the range $3.4-3.8 \mathrm{~nm}$. As for the different precursors, ACNCM- 900 had a larger average pore size than the NCM-900. This was because the low nitrogen content of ACNCM-900 indicated that fewer nitrogen-containing groups were carbonized during the carbonization process and fewer micropores were formed, thus the average pore size was slightly bigger. The corresponding specific surface area, average pore diameter, and total pore volume are listed in the Table 2. The specific surface areas of ACNCM-900 and NCM-900 were calculated to be $788.447 \mathrm{~m}^{2} / \mathrm{g}$ and $798.623 \mathrm{~m}^{2} / \mathrm{g}$. The pore volumes of ACNCM-900 and NCM-900 were $1.376 \mathrm{~cm}^{3} / \mathrm{g}$ and $1.052 \mathrm{~cm}^{3} / \mathrm{g}$. As can be seen from Table 2, the specific surface area and pore volume of carbon materials were higher than the template. The large specific surface area was beneficial for the diffusion and transportation of electrolyte ions.
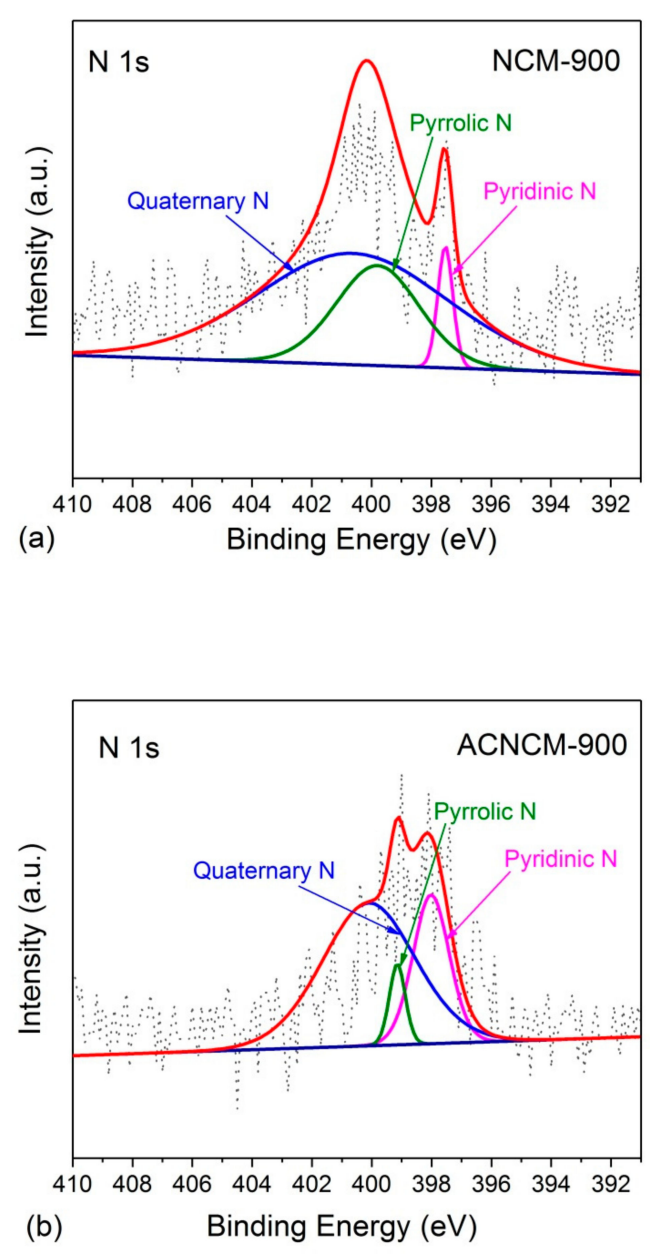

Figure 4. XPS spectra of nitrogen-doped mesoporous carbons (a) NCM-900 and (b) ACNCM-900. 
Table 1. XPS peak analysis of the carbon samples.

\begin{tabular}{cccc}
\hline Samples & $\mathbf{C ~ ( \% )}$ & $\mathbf{O ~ ( \% )}$ & $\mathbf{N ~ ( \% )}$ \\
\hline ACNCM-900 & 93.88 & 4.64 & 1.48 \\
NCM-900 & 89.20 & 5.85 & 4.95 \\
\hline
\end{tabular}
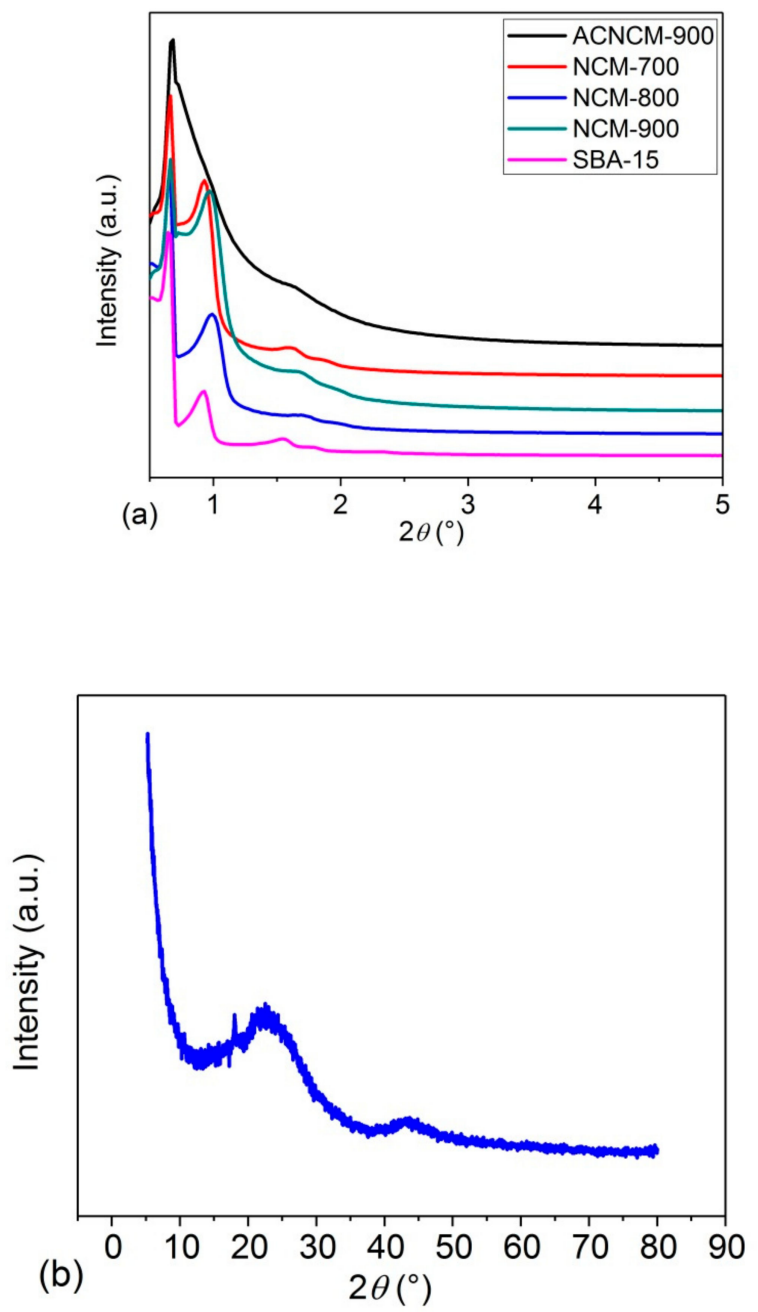

Figure 5. Cont. 

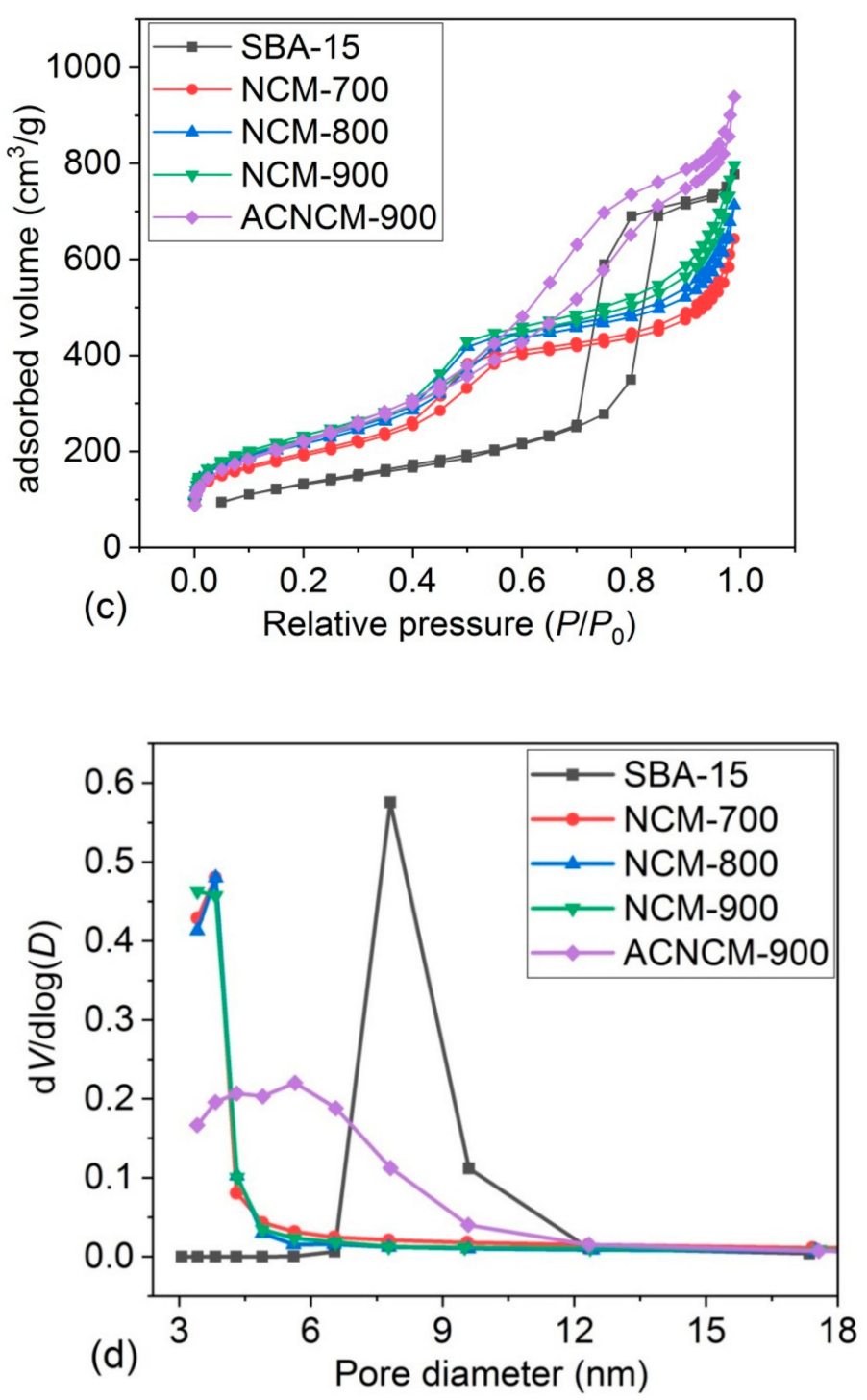

Figure 5. (a) Small angle XRD patterns of ACNCM-900, NCMs, and SBA-15; (b) wide angle XRD pattern of NCM-900; (c) nitrogen adsorption-desorption isotherms, and (d) pore size distribution curves of ACNCM-900, NCMs, and SBA-15.

Table 2. The results of nitrogen adsorption and desorption measurements.

\begin{tabular}{|c|c|c|c|}
\hline \multirow{2}{*}{ Samples } & Specific Surface Area & Total Pore Volume & Average Pore Diameter \\
\hline & $\left(\mathrm{m}^{2} / \mathrm{g}\right)$ & $\left(\mathrm{cm}^{3} / \mathrm{g}\right)$ & $(\mathrm{nm})$ \\
\hline ACNCM-900 & 788.447 & 1.376 & 5.639 \\
\hline NCM-700 & 647.732 & 0.865 & 3.835 \\
\hline NCM-800 & 759.547 & 0.934 & 3.413 \\
\hline NCM-900 & 798.623 & 1.052 & 3.822 \\
\hline SBA-15 & 472.677 & 1.240 & 7.810 \\
\hline
\end{tabular}

\subsection{Electrochemical Performance}

In order to investigate the electrochemical performance of the above four nitrogen-doped carbon materials, cyclic voltammetry $(\mathrm{CV})$ and galvanostatic charge-discharge (GCD) measurements were tested with a three-electrode system in a $0.5 \mathrm{M} \mathrm{H}_{2} \mathrm{SO}_{4}$ electrolyte at room temperature. The $\mathrm{CV}$ curves of the four carbon materials at the scan rate of $5 \mathrm{mV} / \mathrm{s}$ are presented in Figure $6 \mathrm{a}$. It could be seen that the 
curves of the four samples all presented a quasi-rectangular voltammogram shape with the redox peaks, which suggested that double-layer capacitance and pseudocapacitance characteristics were the main energy storage mechanisms of the electrode and that the redox peaks came from pseudocapacitance caused by nitrogen doping [41]. In addition, the NCM-900 had a larger area than the other materials at the rate of $5 \mathrm{mV} / \mathrm{s}$, which indicated that the NCM- 900 had a better electrochemical performance. The GCD curves of the four carbon materials at the current density of $1 \mathrm{~A} / \mathrm{g}$ is presented in Figure $6 \mathrm{~b}$. Furthermore, the shape of the GCD curves was close to an isosceles triangle, which also indicated that the main energy storage mechanism of the electrode was double-layer capacitance. In addition, the NCM-900 had a longer discharge time than other materials at the current density of $1 \mathrm{~A} / \mathrm{g}$.

Figure $6 c$,d shows the cyclic voltammetry and charge-discharge curves, respectively, of NCM-900. The scan rates ranged from 5 to $100 \mathrm{mV} / \mathrm{s}$ in Figure $6 \mathrm{c}$, and the shape of the curves was almost rectangular, which indicated that NCM-900 was suitable as an electrode material due to the reversible adsorption-desorption of free ions. With the scan rate increased, the curve of the sample also presented an approximate rectangular shape, which meant this material was suitable for rapid charge-discharge operation as an electrode material. Figure $6 \mathrm{~d}$ displays the GCD curves of NCM-900 in the current density range from 0.25 to $5 \mathrm{~A} / \mathrm{g}$. The shape of the GCD curves was an isosceles triangle. At a low current density, the electrode materials exhibited the highest specific capacitance, which was contributed to by both double-layer capacitance and pseudocapacitance [26,42]. Upon an increase in current density, the pseudocapacitance gradually disappeared and the shape of isosceles triangle was maintained well, which suggested NCM-900 was a good electrode material.
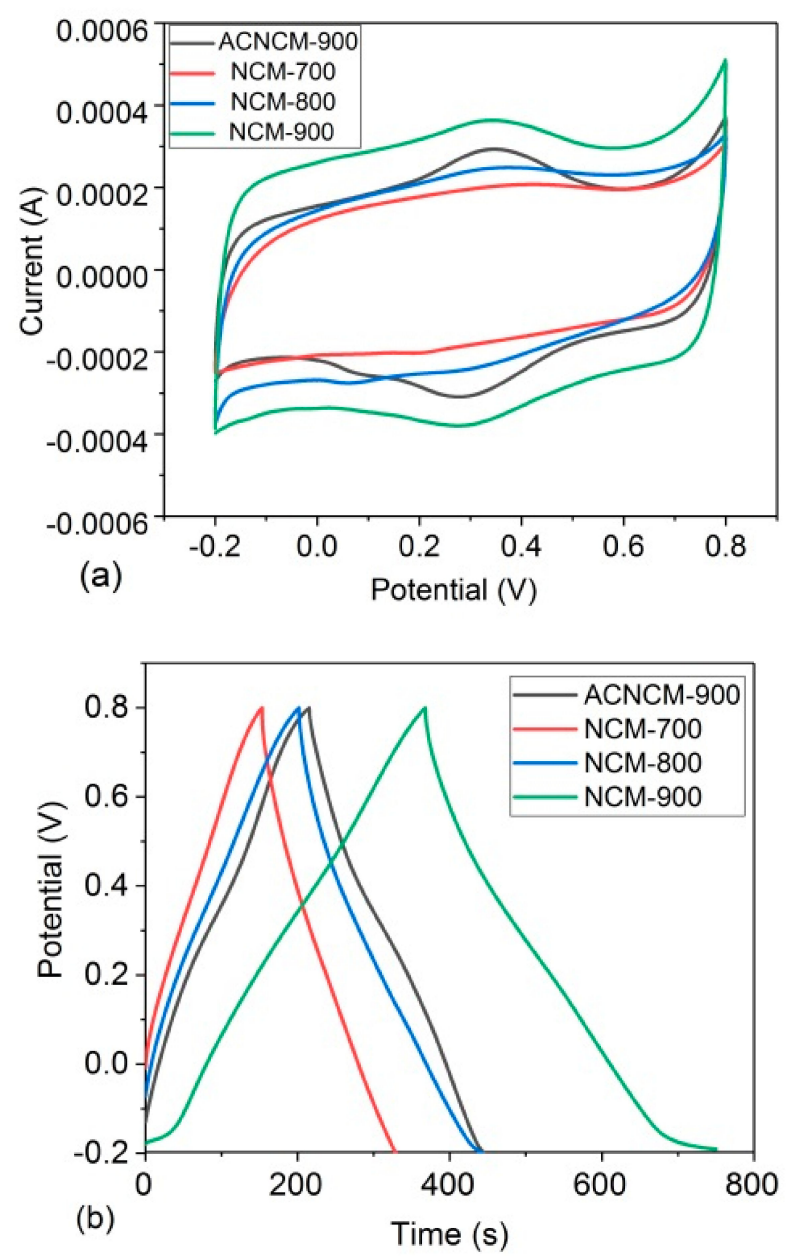

Figure 6. Cont. 

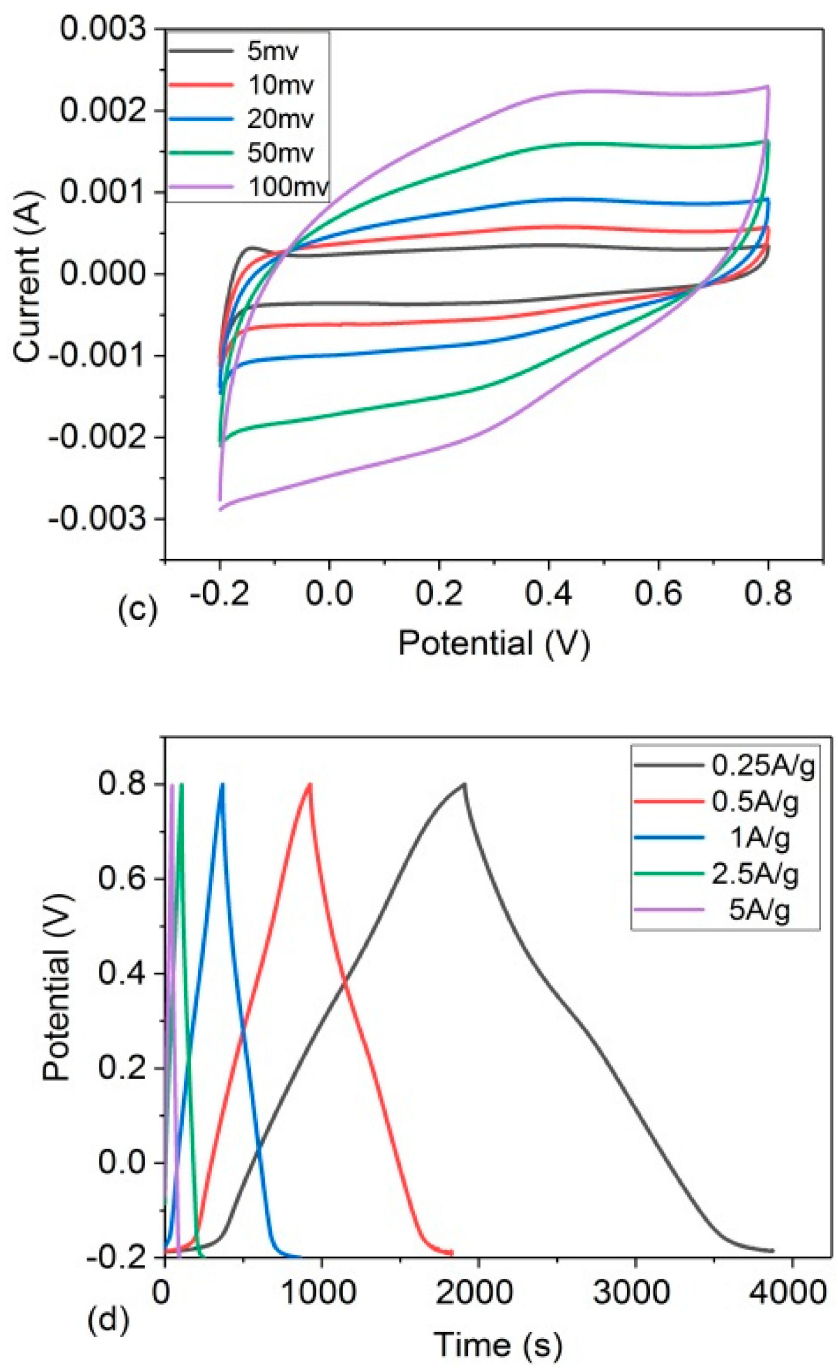

Figure 6. (a) Cyclic voltammetry (CV) curves of four carbon materials at the scan rate of $5 \mathrm{mV} / \mathrm{s}$, (b) galvanic charge-discharge (GCD) curves of four carbon materials at the current density of $1 \mathrm{~A} / \mathrm{g}$, (c) CV curves of NCM-900, and (d) GCD curves of NCM-900.

In order to analyze the data intuitively, we made a comparison of the specific capacitance of different carbon materials in Table 3.

Table 3. The specific capacitance $(\mathrm{F} / \mathrm{g})$ of carbon materials at different current densities.

\begin{tabular}{cccccc}
\hline Samples/Current Density & $\mathbf{0 . 2 5} \mathbf{A} / \mathbf{g}$ & $\mathbf{0 . 5} \mathbf{A} / \mathbf{g}$ & $\mathbf{1 ~ A / g}$ & $\mathbf{2 . 5} \mathbf{~ A / g}$ & $\mathbf{5 ~ A / g}$ \\
\hline NCM-700 & 236 & 205 & 178 & 139 & 96 \\
NCM-800 & 367 & 303 & 244 & 173 & 129 \\
NCM-900 & 460 & 440 & 400 & 322 & 300 \\
ACNCM-900 & 299 & 265 & 233 & 202 & 185 \\
\hline
\end{tabular}

Figure $7 \mathrm{a}$ shows the specific capacity at different current densities of two different nitrogen-containing carbon materials. The data shows that NCM-900 had a better electrochemical performance than ACNCM-900. At the current density of $0.25 \mathrm{~A} / \mathrm{g}$, the specific capacitance of NCM-900 was $460 \mathrm{~F} / \mathrm{g}$, and when the current density was $5 \mathrm{~A} / \mathrm{g}$, the specific capacitance of NCM-900 was $300 \mathrm{~F} / \mathrm{g}$, and the capacitance retention rate was $65.2 \%$, which is reflective of a good capacitance performance.

Figure $7 \mathrm{~b}$ shows the cycling stability of NCM-900 and ACNCM-900 at the current density of $5 \mathrm{~A} / \mathrm{g}$. After 2000 cycles of charge and discharge, the capacitance retention rate of NCM-900 and ACNCM-900 
were $96.1 \%$ and $94.3 \%$, respectively. This suggested that these electrode materials had a good cycle stability and were suitable for use in supercapacitors.

Figure 7c shows the EIS curves of NCM-900 and ACNCM-900 in a $0.5 \mathrm{M} \mathrm{H}_{2} \mathrm{SO}_{4}$ electrolyte and the frequency range from $10^{-2}$ to $10^{5} \mathrm{~Hz}$. The curve contained a semicircle and a straight line. The diameter of the semicircle at high frequencies represented the charge transfer resistance $\left(R_{\mathrm{ct}}\right)$ [43], while the linear slope of the low frequency part of the resistor characterized the diffusion resistance of the electrolyte and protons. The $R_{\mathrm{ct}}$ of NCM-900 and ACNCM-900 were found to be $0.8 \Omega$ and $1.1 \Omega$, respectively. NCM-900 had a lower resistance, which was attributed to the higher nitrogen content, which caused an increase in carbon surface polarity. This was consistent with the CV and GCD test results.

The cyclic voltammetry (CV) and galvanostatic charge-discharge (GCD) of NCM-900 in a two-electrode system are presented in Figure 8a,b, respectively. The CV curves remained as a nearly rectangular shape, which indicated ideal EDLC behavior and good reversibility for the electrolyte ions diffusing rapidly to the interface of the electrode. The GCD curves all exhibited a triangular-like shape even as the current density increased to $5 \mathrm{~A} / \mathrm{g}$, indicating the good coulombic efficiency with superior EDLC performance of NCM-900 [44].

It is confirmed by Figure 8c that NCM-900 had an excellent cycling stability in the two-electrode system and the capacitance retention was $97.5 \%$ after 2000 charge-discharge cycles at a current density of $5 \mathrm{~A} / \mathrm{g}$. The specific capacitance for NCM-900 calculated from the GCD curve is also exhibited in this graph, where a high capacitance of $317 \mathrm{~F} / \mathrm{g}$ was observed at $0.25 \mathrm{~A} / \mathrm{g}$, and the specific capacitance was $200 \mathrm{~F} / \mathrm{g}$ was observed when the current density was at $5 \mathrm{~A} / \mathrm{g}$.
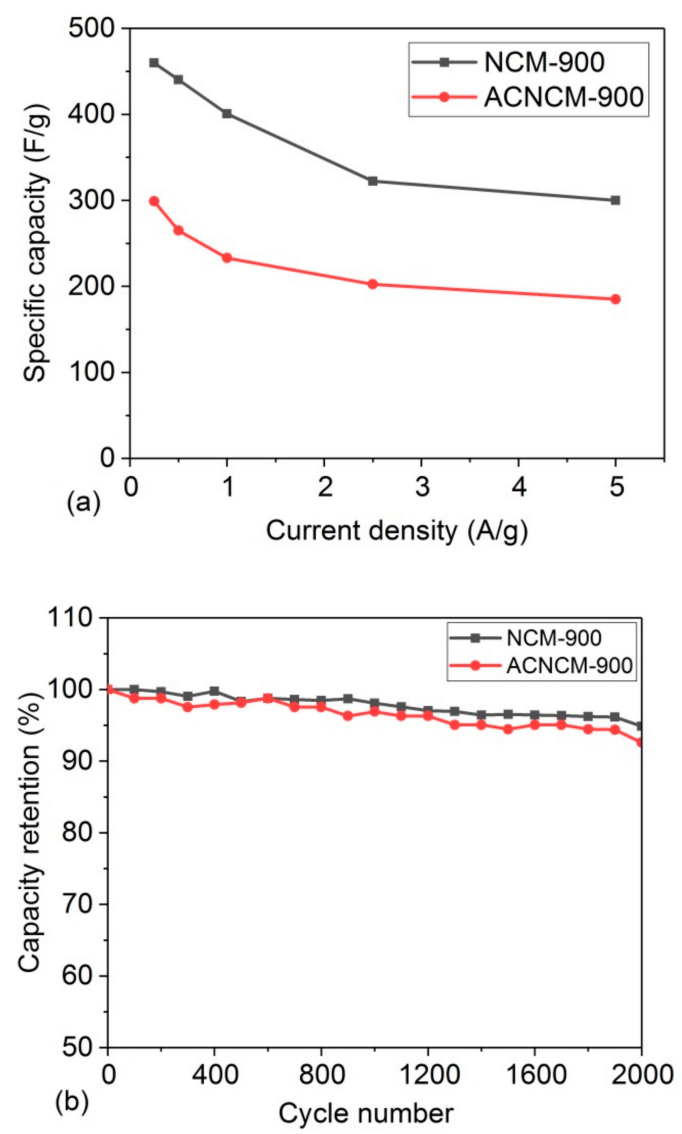

Figure 7. Cont. 


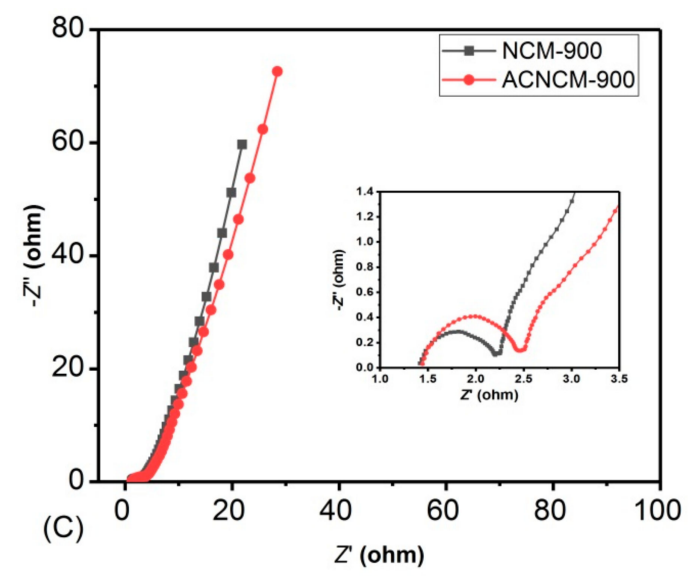

Figure 7. (a) Specific capacity of NCM-900 and ACNCM-900 at different current densities, (b) cycle stability of NCM-900 and ACNCM-900 after 2000 cycles at $5 \mathrm{~A} / \mathrm{g}$, and (c) electrochemical impedance spectroscopy (EIS) of NCM-900 and ACNCM-900.
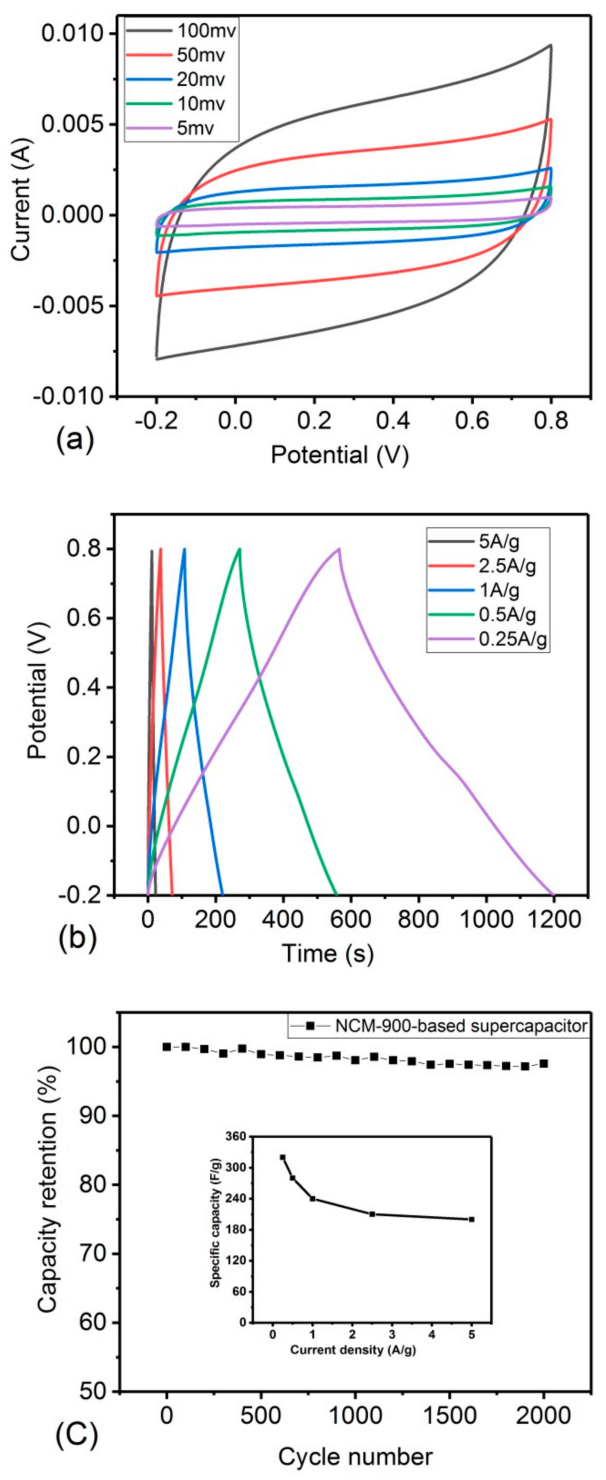

Figure 8. Cont. 


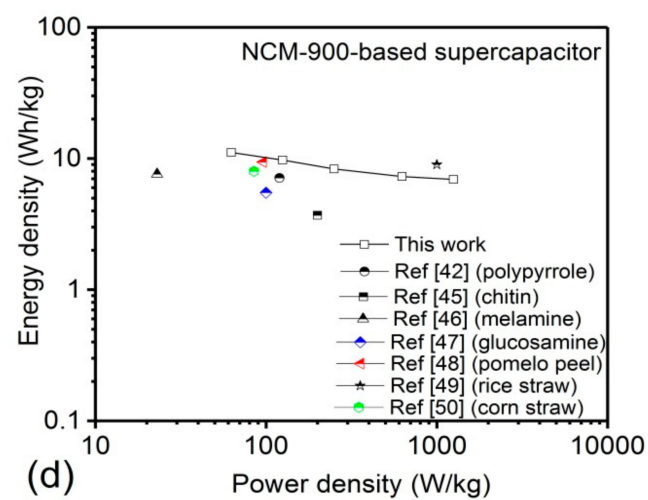

Figure 8. (a) CV curves of NCM-900 at different scan rates, (b) GCD curves of NCM-900 at different current densities, (c) cycling stability performance at a current density of $5 \mathrm{~A} / \mathrm{g}$ to 2000 cycles for NCM-900-based supercapacitors in $6 \mathrm{M} \mathrm{KOH}$ electrolyte (inset graph is the specific capacity of NCM-900 at different current densities), and (d) Ragon plots for NCM-900-based supercapacitor with reported supercapacitors constructed from other kinds of carbon materials.

The results of the energy densities and power densities of the supercapacitors calculated for various current densities are shown as Ragone plots in Figure 8d. There was a decreasing trend in energy density with an increase of power density. The energy density of the NCM-900-based supercapacitor was calculated to be over $11.1 \mathrm{Wh} / \mathrm{kg}$ at $0.25 \mathrm{~A} / \mathrm{g}$ with a power density of $62.5 \mathrm{~W} / \mathrm{kg}$. The energy density of the NCM-900-based supercapacitor was $7.1 \mathrm{Wh} / \mathrm{kg}$ at a high current density of $5 \mathrm{~A} / \mathrm{g}$ with a power density of $1250 \mathrm{~W} / \mathrm{kg}$, which is highly competitive with most carbon-based materials obtained from other precursors, as shown in Figure 8d [42,45-50]. The results confirmed that $\mathrm{N}$-doped carbons with an ordered pore structure and a high surface area could enable higher energy and power densities, and NCM-900 is a promising candidate for capacitive energy storage and conversion.

\section{Conclusions}

The morphology, structure, and electrochemical properties of the four samples prepared using benzoxazine were characterized, and the impact of the carbonization temperature and nitrogen content on the electrochemical properties were investigated. The NCM-900 had the highest specific capacitance of $460 \mathrm{~F} / \mathrm{g}$ in a $0.5 \mathrm{M} \mathrm{H}_{2} \mathrm{SO}_{4}$ electrolyte at the current density of $0.25 \mathrm{~A} / \mathrm{g}$. At the current density of $5 \mathrm{~A} / \mathrm{g}$, its specific capacitance was still able to retain $300 \mathrm{~F} / \mathrm{g}$ and the capacitance retention rate was $65.2 \%$. Moreover, NCM-900 presented a good stability with a $96.1 \%$ capacitance retention after 2000 cycles at the current density of $5 \mathrm{~A} / \mathrm{g}$ in a three-electrode system. Furthermore, the high specific capacitance, comparable energy/power densities, and excellent cycling stability of NCM-900 were exhibited using a symmetrical electrode system. Therefore, NCM-900 is a promising candidate for high-performance supercapacitors.

Author Contributions: This paper was accomplished based on collaborative work of the authors. H.Z. performed the experiments, analyzed the data, interpreted the experimental results and wrote the paper. L.X. contributed to the experimental design. L.X. and G.L. supervised the entire research progress. All authors have read and agreed to the published version of the manuscript.

Funding: This research was funded by the National Natural Science Foundation of China grant number (51703205).

Conflicts of Interest: The authors declare no conflict of interest. 


\section{References}

1. Aricò, A.; Bruce, P.; Scrosati, B.; Tarascon, J.; Schalkwijk, W. Anostructured materials for advanced energy conversion and storage devices. Nat. Mater. 2005, 4, 366-377. [CrossRef]

2. Zhang, L.; Zhao, X. Carbon-based materials as supercapacitor electrodes. Chem. Soc. Rev. 2009, 9, $2520-2531$. [CrossRef] [PubMed]

3. Zhai, Y.; Dou, Y.; Zhao, D.; Fulvio, P.F.; Mayes, R.T.; Dai, S. Carbon materials for chemical capacitive energy storage. Adv. Mater. 2011, 43, 4828-4850. [CrossRef] [PubMed]

4. Simon, P.; Gogotsi, Y. Capacitive energy storage in nanostructured carbon-Electrolyte systems. Acc. Chem. Res. 2012, 46, 1094-1103. [CrossRef] [PubMed]

5. Merlet, C.; Rotenberg, B.; Madden, P.; Tabema, P.; Simon, P.; Gogotsi, Y.; Salanne, M. On the molecular origin of supercapacitance in nanoporous carbon electrodes. Nat. Mater. 2012, 11, 306-310. [CrossRef]

6. Zhao, L.; Fan, L.; Zhou, M.; Guan, H.; Qiao, S.; Antonietti, M.; Titirici, M. Nitrogen-containing hydrothermal carbons with superior performance in supercapacitors. Adv. Mater. 2010, 45, 5202-5206. [CrossRef]

7. Liu, M.; Qin, Z.; Yang, X.; Lin, Z.; Guo, T. Fabricating controllable hierarchical pores on smooth carbon sheet for synthesis of supercapacitor materials. Vacuum 2019, 168, 108806. [CrossRef]

8. Duan, J.; Chen, S.; Jaroniec, M.; Qiao, S. Heteroatom-doped graphene-based materials for energy-relevant electrocatalytic processes. ACS Catal. 2015, 5, 5207-5234. [CrossRef]

9. Béguin, F.; Presser, V.; Balducci, A.; Frackowiak, E. Carbons and electrolytes for advanced supercapacitors. Adv. Mater. 2014, 26, 2283. [CrossRef]

10. Wang, X.; Sun, G.; Routh, P.; Kim, D.; Huang, W.; Chen, P. Heteroatom-doped graphene materials: Syntheses, properties and applications. Chem. Soc. Rev. 2014, 43, 7067-7098. [CrossRef]

11. Jia, S.; Wang, Y.; Xin, G.; Zhou, S.; Tian, P.; Zang, J. An efficient preparation of N-doped mesoporous carbon derived from milk powder for supercapacitors and fuel cells. Electrochim. Acta 2016, 196, 527-534. [CrossRef]

12. Yuan, D.; Zhou, T.; Zhou, S.; Zou, W.; Mo, S.; Xia, N. Nitrogen-enriched carbon nanowires from the direct carbonization of polyaniline nanowires and its electrochemical properties. Electrochem. Commun. 2011, 13, 242-246. [CrossRef]

13. Hou, J.; Cao, C.; Idrees, F.; Ma, X. Hierarchical porous nitrogen-doped carbon nanosheets derived from silk for ultrahigh-capacity battery anodes and supercapacitors. ACS Nano 2015, 9, 2556-2564. [CrossRef] [PubMed]

14. Yang, Z.; Ren, J.; Zhang, Z.; Chen, X.; Guan, G.; Qiu, L.; Zhang, Y.; Peng, H. Recent advancement of nanostructured carbon for energy applications. Chem. Rev. 2015, 115, 5159-5223. [CrossRef] [PubMed]

15. Lin, Z.; Waller, G.; Liu, Y.; Liu, M. Facile synthesis of nitrogen-doped graphene via pyrolysis of graphene oxide and urea, and its electrocatalytic activity toward the oxygen-reduction reaction. Adv. Energy Mater. 2012, 2, 884-888. [CrossRef]

16. Lai, L.; Potts, J.; Zhan, D.; Wang, L. Exploration of the active center structure of nitrogen-doped graphene-based catalysts for oxygen reduction reaction. Energy Environ. Sci. 2012, 5, 7936-7942. [CrossRef]

17. Hou, S.; Cai, X.; Wu, H.; Yu, X. Nitrogen-doped graphene for dye-sensitized solar cells and the role of nitrogen states in triiodide reduction. Energy Environ. Sci. 2013, 6, 3356-3362. [CrossRef]

18. Choi, C.; Chung, M.; Park, S.; Woo, S. Enhanced electrochemical oxygen reduction reaction by restacking of N-doped single graphene layers. RSC Adv. 2013, 4, 4246-4253. [CrossRef]

19. Sheng, Z.; Shao, L.; Chen, J.; Bao, W.; Wang, F.; Xia, X. Catalyst-free synthesis of nitrogen-doped graphene via thermal annealing graphite oxide with melamine and its excellent electrocatalysis. ACS Nano 2011, 5, 4350-4358. [CrossRef]

20. Shen, W.; Fan, W. Nitrogen-containing porous carbons: Synthesis and application. J. Mater. Chem. A 2012, 1, 999-1013. [CrossRef]

21. Si, Y.; Yu, J.; Tang, X.; Ge, J.; Ding, B. Ultralight nanofibre-assembled cellular aerogels with superelasticity and multifunctionality. Nat. Commun. 2014, 5, 5802. [CrossRef] [PubMed]

22. Thubsuang, U.; Ishida, H.; Wongkasemjit, S.; Chaisuwan, T. Improvement in the pore structure of polybenzoxazine-based carbon xerogels through a silica templating method. J. Porous Mater. 2014, 21, 401-411. [CrossRef] 
23. Wan, L.; Wang, J.; Xie, L.; Sun, Y.; Li, K. Nitrogen-enrichedhierarchically porous carbons preparedfrom polybenzoxazine for high-performance supercapacitors. ACS Appl. Mater. Interfaces 2014, 6, 15583-15596. [CrossRef] [PubMed]

24. Taskin, O.; Kiskan, B.; Aksu, A.; Balkis, N.; Weber, J.; Yagci, Y. Polybenzoxazine: A powerful tool for removal of mercury salts from water. Chem. Eur. J. 2014, 20, 10953-10958. [CrossRef] [PubMed]

25. Gao, F.; Ying, J.; Xu, X.; Cai, L. Nitrogen-enriched carbon nanofibers derived from polyaniline and their capacitive properties. Appl. Sci. 2018, 8, 1079. [CrossRef]

26. Deng, Y.; Xie, Y.; Zou, K.; Ji, X. Review on recent advances in nitrogen-doped carbons: Preparations and applications in supercapacitors. J. Mater. Chem. A 2016, 4, 1144-1173. [CrossRef]

27. Lee, J.; Han, S.; Hyeon, T. Synthesis of new nanoporous carbon materials using nanostructured silica materials as templates. J. Mater. Chem. 2004, 14, 478-486. [CrossRef]

28. Wu, K.; Liu, Q. Nitrogen-doped mesoporous carbons for high performancesupercapacitors. Appl. Surf. Sci. 2016, 379, 132-139. [CrossRef]

29. Zhang, C.; Deng, Y.; Zhang, Y.; Yang, P.; Gu, Y. Study on products and reaction paths for synthesis of 3,4-dihydro-2h-3-phenyl-1,3-benzoxazine from phenol, aniline and formaldehyde. Chin. Chem. Lett. 2015, 26, 348-352. [CrossRef]

30. Zhao, J.; Lai, H.; Lyu, Z.; Jiang, Y.; Xie, K.; Wang, X.; Wu, Q.; Yang, L.; Jin, Z.; Ma, Y.; et al. Hydrophilic hierarchical nitrogen-doped carbon nanocages for ultrahigh supercapacitive performance. Adv. Mater. 2015, 27, 3541-3545. [CrossRef]

31. Xia, Y.; Mokaya, R. Synthesis of ordered mesoporous carbon and nitrogen-doped carbon materials with graphitic pore walls via a simple chemical vapor deposition method. Adv. Mater. 2004, 16, 1553-1558. [CrossRef]

32. Greczynski, G.; Hultman, L. X-ray photoelectron spectroscopy: Towards reliable binding energy referencing. Prog. Mater. Sci. 2019, 107, 100591. [CrossRef]

33. Yu, S.; Liu, D.; Zhao, S.; Bao, B.; Jin, C.; Huang, W.; Shen, Z. Synthesis of wood derived nitrogen-doped porous carbon-polyaniline composites for supercapacitor electrode materials. RSC Adv. 2015, 5, 30943-30949. [CrossRef]

34. Huang, G.; Wang, Y.; Zhang, T.; Wu, X.; Cai, J. High-performance hierarchical N-doped porous carbons from hydrothermally carbonized bamboo shoot shells for symmetric supercapacitors. J. Taiwan Inst. Chem. Eng. 2019, 96, 672-680. [CrossRef]

35. Lu, Y.; Zhang, F.; Zhang, T.; Leng, K.; Zhang, L.; Yang, X.; Chen, Y. Synthesis and supercapacitor performance studies of $\mathrm{N}$-doped graphene materials using o-phenylenediamine as the double-N precursor. Carbon 2013, 63, 508-516. [CrossRef]

36. Chen, H.; Liu, D.; Shen, Z.; Bao, B.; Zhao, S.; Wu, L. Functional biomass carbons with hierarchical porous structure for supercapacitor electrode materials. Electrochim. Acta 2015, 180, 241-251. [CrossRef]

37. Chang, J.; Gao, Z.; Zhao, W.; Guo, L.; Tang, Y.; Wu, D.; Xu, F.; Jiang, K. Nitrogen doped microporous carbons with tunable and selective performances in supercapacitor and heterogeneous catalysis. Electrochim. Acta 2016, 190, 912-922. [CrossRef]

38. Zhao, Q.; Wang, X.; Wu, C.; Liu, J.; Wang, H.; Gao, J.; Zhang, Y.; Su, H. Supercapacitive performance of hierarchical porous carbon microspheres prepared by simple one-pot method. J. Power Sources 2014, 254, 10-17. [CrossRef]

39. Cai, J.; Qi, J.; Yang, C.; Zhao, X. Poly (vinylidene chloride)-based carbon with ultrahigh microporosity and outstanding performance for $\mathrm{CH} 4$ and $\mathrm{H} 2$ storage and $\mathrm{CO}_{2}$ capture. ACS Appl. Mater. Interfaces 2014, 6, 3703-3711. [CrossRef]

40. Liang, J.; Du, X.; Gibson, C.; Du, X.; Qiao, S. N-doped graphene natively grown on hierarchical ordered porous carbon for enhanced oxygen reduction. Adv. Mater. 2013, 25, 6226-6231. [CrossRef]

41. Wang, Y.; Song, Y.; Xia, Y. Electrochemical capacitors: Mechanism, materials, systems, characterization and applications. Chem. Soc. Rev. 2016, 45, 5925-5950. [CrossRef] [PubMed]

42. Chen, L.; Zhang, X.; Liang, H.; Kong, M.; Guan, Q.; Chen, P.; Yu, S. Synthesis of nitrogen-doped porous carbon nanofibers as an efficient electrode material for supercapacitors. ACS Nano 2012, 6, 7092-7102. [CrossRef]

43. Wang, D.; Wang, Y.; Liu, H.; Xu, W.; Xu, L. Unusual carbon na nomesh constructed by interconnected carbon nanocages for ionic liquid-based supercapacitor with superior rate capability. Chem. Eng. J. 2018, 342, 474-483. [CrossRef] 
44. Shu, Y.; Maruyama, J.; Iwasaki, S.; Li, C.; Shen, Y.; Uyama, H. Hierarchical activated green carbons from abundant biomass waste for symmetric supercapacitors. Bull. Chem. Soc. Jpn. 2017, 90, 1058-1066. [CrossRef]

45. Raj, C.; Rajesh, M.; Manikandan, R.; Yu, K.; Anusha, J.; Ahn, J.; Kim, D.; Park, S.; Kim, B. High electrochemical capacitor performance of oxygen and nitrogen enriched activated carbon derived from the pyrolysis and activation of squid gladius chitin. J. Power Sources 2018, 386, 66-76. [CrossRef]

46. Li, M.; Xue, J. Integrated Synthesis of Nitrogen-Doped Mesoporous Carbon from Melamine Resins with Superior Performance in Supercapacitors. J. Phys. Chem. C 2014, 118, 2507-2517. [CrossRef]

47. Fan, X.; Yu, C.; Yang, J.; Ling, Z.; Qiu, J. Hydrothermal synthesis and activation of graphene-incorporated nitrogen-rich carbon composite for high-performance supercapacitors. Carbon 2014, 70, 130-141. [CrossRef]

48. Liang, Q.; Ye, L.; Huang, Z.; Xu, Q.; Bai, Y.; Kang, F.; Yang, Q. A honeycomb-like porous carbon derived from pomelo peel for use in high-performance supercapacitors. Nanoscale 2014, 6, 13831-13837. [CrossRef] [PubMed]

49. Liu, S.; Zhao, Y.; Zhang, B.; Xia, H.; Zhou, J.; Xie, W.; Li, H. Nano-micro carbon spheres anchored on porous carbon derived from dual biomass as high rate performance supercapacitor electrodes. J. Power Sources 2018, 381, 116-126. [CrossRef]

50. Qiu, Z.; Wang, Y.; Bi, X.; Zhou, T.; Zhou, J.; Zhao, J.; Miao, Z.; Yi, W.; Fu, P.; Zhuo, S. Biochar-based carbons with hierarchical micro-meso-macro porosity for high rate and long cycle life supercapacitors. J. Power Sources 2018, 376, 82-90. [CrossRef]

(C) 2020 by the authors. Licensee MDPI, Basel, Switzerland. This article is an open access article distributed under the terms and conditions of the Creative Commons Attribution (CC BY) license (http://creativecommons.org/licenses/by/4.0/). 